Review

\title{
Field Testing Protocols for Talent Identification and Development in Basketball-A Systematic Review
}

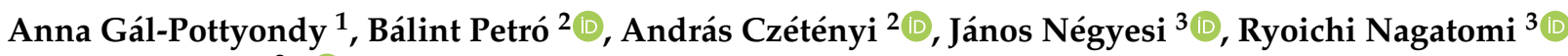 \\ and Rita M. Kiss ${ }^{2, *(D)}$ \\ 1 Doctoral School of Sport Sciences, University of Physical Education, HU-1123 Budapest, Hungary; \\ gpottyanna@gmail.com \\ 2 Department of Mechatronics, Optics and Engineering Informatics, Faculty of Mechanical Engineering, \\ Budapest University of Technology and Economics, HU-1111 Budapest, Hungary; petro@mogi.bme.hu (B.P.) \\ andras.czetenyi@gmail.com (A.C.) \\ 3 Division of Biomedical Engineering for Health and Welfare, Tohoku University Graduate School of \\ Biomedical Engineering, Sendai 980-8575, Japan; negyesi@tohoku.ac.jp (J.N.); \\ nagatomi@med.tohoku.ac.jp (R.N.) \\ * Correspondence: rita.kiss@mogi.bme.hu
}

Citation: Gál-Pottyondy, A.; Petró,

B.; Czétényi, A.; Négyesi, J.;

Nagatomi, R.; Kiss, R.M. Field Testing

Protocols for Talent Identification and Development in Basketball-A

Systematic Review. Appl. Sci. 2021, 11, 4340. https://doi.org/10.3390/ app11104340

Academic Editor: Vaclav Bunc

Received: 8 April 2021

Accepted: 6 May 2021

Published: 11 May 2021

Publisher's Note: MDPI stays neutral with regard to jurisdictional claims in published maps and institutional affiliations.

Copyright: (c) 2021 by the authors. Licensee MDPI, Basel, Switzerland. This article is an open access article distributed under the terms and conditions of the Creative Commons Attribution (CC BY) license (https:// creativecommons.org/licenses/by/ $4.0 /)$.

\begin{abstract}
Basketball is one of the most popular team sports in the world. A wide variety of athletic skills can be valuable indicators of a talented player. Testing these skills help trainers and scouts to make the best decisions during both youth and adult player selection of different competitive levels and field positions. However, scientific data regarding the association between field tests results and match statistics is sparse. We conducted a systematic review to logically summarize the physical field tests of athletic abilities and anthropometric measures used in basketball in different player positions at different levels, and to determine whether test results may correlate with match statistics. A comprehensive electronic literature search was performed via three electronic databases (PubMed, GoogleScholar, SportDiscus). The CASP checklist was used for checking the quality of reporting for all included articles. Based on 39 studies, it could be supported that the agility, speed and jumping test values seem to be crucial measures for basketball players. Anthropometry appeared to be the strongest discriminative factor between basketball positions, therefore, these values need to be significantly considered during selection. Moreover, the maturity status is also an important influencing factor for U-18 teams. In general, we found that successful players can be identified by their nonplanned agility and reactive power, considering that these factors affect match outcomes the most at the same competitive level.
\end{abstract}

Keywords: basketball; match performance; physical testing; playing level; playing position

\section{Introduction}

Trainers, managers, and scouts need to make difficult but determinative decisions during selection or before the transfer of players. The "trainers' eyes" are essential and necessary to evaluate the potential talents, however, it is somewhat subjective, and a lot depends on the trainers' experience level. Performing field-, and laboratory tests are excellent ways to get an objective picture of the basketball players' athletic abilities and sport-specific skills. During the season, laboratory testing is usually not needed because field testing is sufficient in most cases. The literature consists of several reliable and valid physical field tests to assess basketball-related anaerobic and aerobic fitness and sport-specific skills that may support the most determinative selection of the potential talents [1-5]. The sport-specific tests depend on the nature (size of the pitch, movement material, etc.) of the particular sport. Basketball-specific tests may consist of trials on a shorter distance, with multiple changes-of-direction (COD), jumps and shots. Even though several tests adopted from other sports might be also useful, experts should consider before 
testing whether the test is appropriate for basketball. For example, the Cooper test is one of the most commonly used fitness tests to measure the fitness levels of soccer players [6], long-distance runners [7], judokas [8] or Olympic wrestlers [9], however, it is meaningless in basketball players, because repeated sprints with quick COD are considered to be the key performance determinant in basketball [10-12]. Many field tests are also applicable for monitoring the training load and determining the on-field physical conditions of the players [13-15]. Besides the cost-, and time-effectiveness of field tests, their simplicity allows trainers and researchers to perform them before, after and even during the training. The application of a well-planned testing protocol can provide an objective picture of the athletes' athletes' performance, which might be also used to motivate players. Moreover, field tests can be also used to screen for overtraining, thus, prevention of overreaching can reduce the risk of injury.

Since basketball is among the most popular team sports globally, considerable research efforts have been made exploring basketball players' athletic abilities and sport-specific skills. To obtain relevant results and make valid comparisons, trainers and researchers should also consider the differences between athletes' skills based on their playing positions and playing levels. Consequently, the extent of such skills can indicate the most appropriate playing position for the athlete and may support the athlete to consider competing at higher playing levels. For example, lower-body power, agility and reduced lower-body imbalances are required to execute more proficient on-court movements which is essential at higher playing levels [16], therefore, these variables might be useful indicators during talent selection and development.

On the other hand, it is still unclear whether field test results are associated with match statistics. Even though a previous study [17] found that the variance of agility and sprinting tests correlated with playing quality, longitudinal follow-up studies are required to determine whether improvement in field test results also directly indicates better match performance. Overall, speed and agility are essential fitness components, especially for smaller basketball players [18], nevertheless, player position, playing level, age and gender need to be considered when analyzing the data of field tests.

Even though there is considerable interest from both researchers and sports experts, no review can be found on the field tests of athletic abilities and sport-specific skills used in basketball in different player positions, playing levels and match performance. Therefore, the purpose of the present systematic review was to summarize the abilities and features of basketball field-testing studies that can support distinguishing between playing positions and playing levels. We also tried to answer the question whether the results of such field tests may correlate with match statistics.

\section{Materials and Methods}

\subsection{Data Sources and Search Strategy}

Three electronic databases (PubMed, GoogleScholar, SportDiscus) were searched for publications dated 2008-2020 with the search performed on 12-13 July 2020. Keywords were basketball, agility, power testing, physical assessment, speed performance, jump test and additional synonyms of these terms. Search terms were modified according to the required search format of each database. As an example, a full electronic search strategy for the GoogleScholar database is provided here. In the Advanced search option, the following terms were added with Boolean conjunction to search for in "All in Title": basketball, agility OR speed OR jump OR assessment OR testing OR monitoring OR power. We used some extra articles which we have found for our other literature research on similar topics. The search was refined to journal and book publications. Key search terms were identified and agreed upon by A.G.-P. and R.M.K.; the electronic search and downloading of results were carried out by A.G.-P. Screening, eligibility check of materials and data extraction were carried out by A.G.-P., B.P., J.N. and A.C. Following the removal of duplicates, the identified materials were screened based on title and abstract. 


\subsection{Inclusion and Exclusion Criteria}

To meet the inclusion criteria for the review, full-text peer-reviewed English manuscripts investigating healthy basketball players and analyzed the physical field tests of athletic abilities in different player positions or at different levels were considered. We also reviewed the literature to identify potential associations between test results and the values of basketball match statistics to evaluate which physical demands make the player more successful.

The exclusion criteria were (1) language of the article was not English, (2) participants were disabled basketball players, or the study focus was injury or injury prevention, (3) the article was an impact study, (4) the main topic was tactical or technical basketball testing or mental and habitual testing, (5) the primary evaluation was not based on an objective measure (e.g., a subjective, visual video analysis) and (6) the main topic was the comparison of basketball with other sports.

\subsection{Data Extraction and Analysis}

After screening, information extracted from the selected publications include: (1) author and date, (2) applied physical tests, (3) results of the testing, (4) group size of participants, (5) age and sex of groups, (6) practical advice on testing. The extracted data are available in Supplementary material 1 . We identified the tests, abilities, and features that can support distinguishing between playing positions and playing levels and we also tried to answer whether the results of such field tests may correlate with match statistics. Each topic is presented as a separate section in which we evaluated the different skills and abilities of basketball players.

\subsection{Study Quality, Risk of Bias}

The articles' quality was evaluated using the Critical Appraisal Skills Programme (CASP) quality-assessment tool for qualitative studies (http:/ / www.casp-uk.net/\#!casptools-checklists/c18f8, accessed on 10 January 2021). The checklist included the following items: "Clear statement of the aims of research"; "Appropriate qualitative methodology"; "Appropriate research design"; "Appropriate recruitment strategy"; "Data collection addressed the research issue"; "Relationship between researcher and participants"; "Ethical approval"; "Data analysis"; "Clear statement of findings"; and "Valuable contribution". The overall quality assessment of "high", "medium" or "low" was based on the evaluation by two reviewers (BP and JN) and active discussion until consensus was reached in the case of rating discrepancies. We did not undertake a risk of bias assessment because the included studies were not randomized controlled studies and because our evidence synthesis method is outside of systematic reviews.

\section{Results}

The search in the GoogleScholar database yielded 761 records; in the PubMed database, 229 records; in the SportDiscus database, 336 records (Figure 1). Six additional records from an initial investigation were also included. After removing duplicates, 1019 records remained. We screened out 745 records based on their title and abstract. From the remaining 274 records, only 233 full texts were available. During the eligibility check, we excluded 107 records based on the exclusion criteria. From the remaining 126 records, 40 records met the inclusion criteria; however, one study was excluded as a result of the quality assessment. Therefore 39 studies were included in the manuscript. Additionally, a handbook from Drinkwater et al. [13] is also mentioned in the article. 


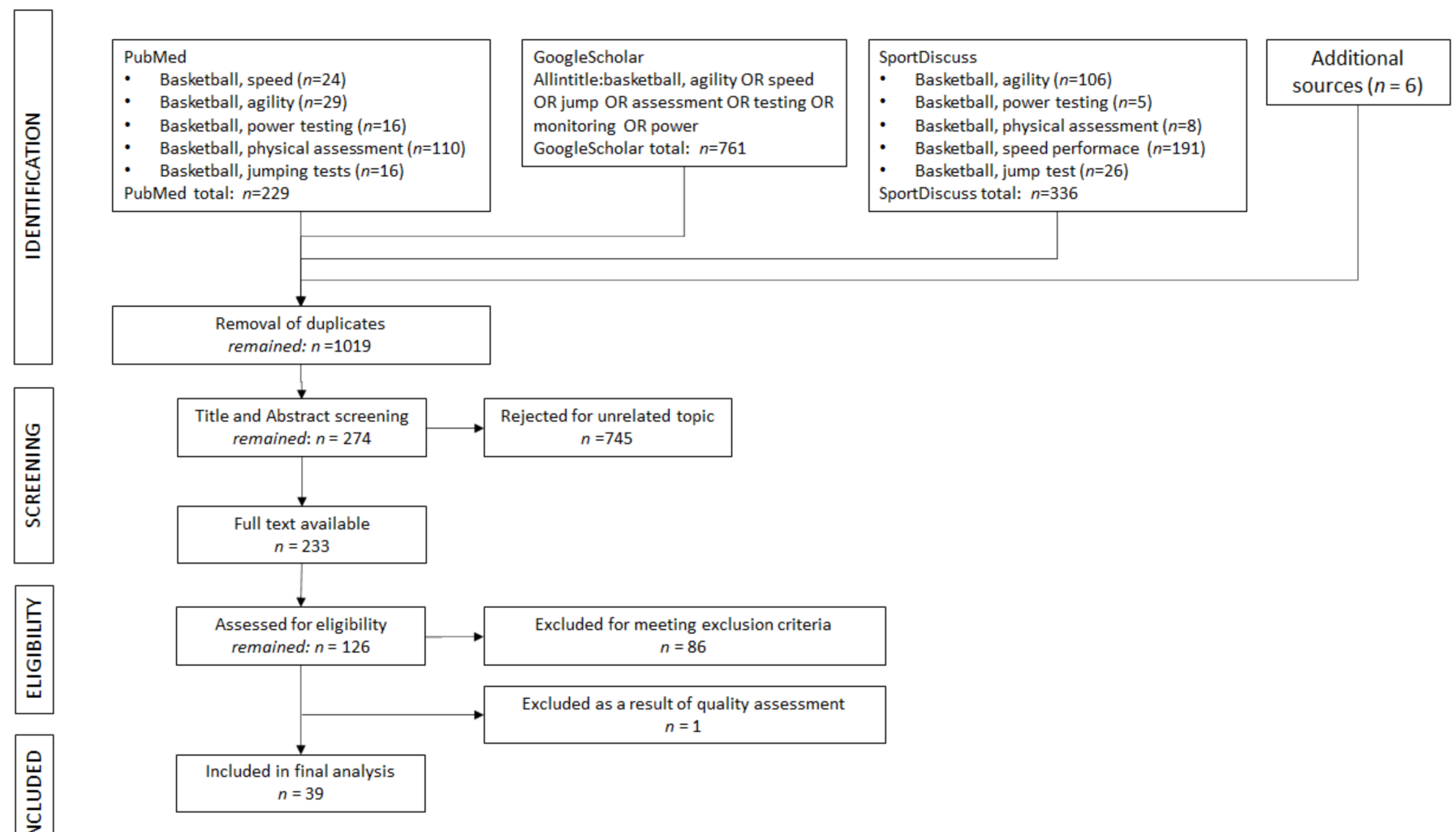

Figure 1. Flow diagram illustrating studies for inclusion in the review study.

Figure 2 summarizes the results of the quality assessment for each included article. Thirty-seven studies received "high" quality ratings. Six articles [4,15,19-22] did not report clearly if ethical approval was obtained for the study. Two out of these six articles had other quality issues regarding data analysis, or they also failed to provide a clear statement of the findings; therefore, they received "medium" quality ratings. During synthesizing the results, we paid attention to the quality assessment in weighing the strength of evidence from individual studies, e.g., noting a small sample size as a possible source of bias.

\subsection{Differences between Playing Positions}

The data are inconsistent concerning the differences in physiological and biomechanical characteristics of basketball players playing at different positions; in some $[13,14]$ but not all cases [15], there was an effect of player position on these parameters. For example, perimeter players' external playing load is higher than others due to the more common decelerating actions. Therefore, position-based specific training processes are strongly recommended [21]. Contrary, Heishman et al. [15] found no differences in external training load between playing positions measured by weekly countermovement jump (CMJ) tests during a 5-week pre-season training. Studies that reported differences between playing positions are summarized in Table 1. 


\begin{tabular}{|c|c|c|c|c|c|c|c|c|c|c|c|}
\hline & 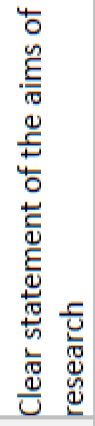 & 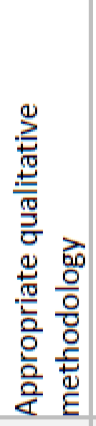 & 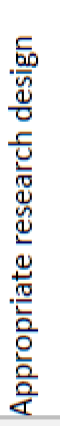 & 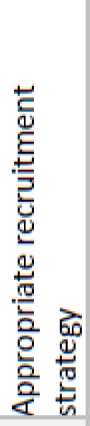 & 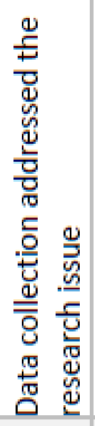 & 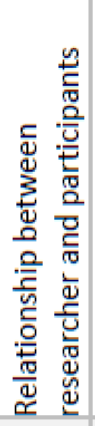 & 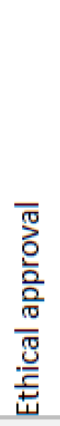 & 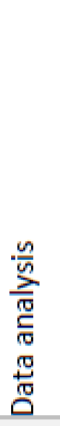 & 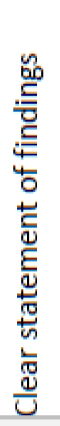 & 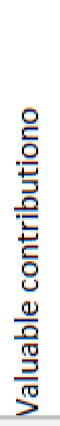 & 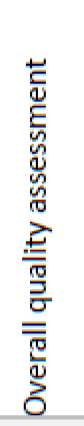 \\
\hline Abdelkrim 2010 & 1 & 1 & 1 & 1 & 1 & 1 & 1 & 1 & 1 & 1 & high \\
\hline Aksovic 2020 & 1 & 1 & 1 & 1 & 1 & 1 & 1 & 1 & 1 & 1 & high \\
\hline Arede 2018 & 1 & 1 & 1 & 1 & 1 & 1 & 1 & 1 & $?$ & $?$ & high \\
\hline Begu 2018 & 1 & 1 & 1 & 1 & 1 & 1 & 0 & 0 & 1 & $?$ & high \\
\hline Boone, Bourgois 2013 & 1 & 1 & 1 & 1 & 1 & 1 & 1 & 1 & 1 & 1 & high \\
\hline Ferioli 2018 & $?$ & 1 & 1 & 1 & 1 & 1 & 1 & 1 & 1 & 1 & high \\
\hline Ferioli 2019 & 1 & 1 & 1 & 1 & 1 & 1 & 1 & 1 & 1 & 1 & high \\
\hline Dawes 2016 & 1 & 1 & 1 & $?$ & 1 & 1 & 1 & 1 & 1 & $?$ & high \\
\hline Delextrat 2008 & 1 & 1 & 1 & $?$ & 1 & 1 & 1 & 1 & 1 & $?$ & high \\
\hline Delextrat 2009 & 1 & 1 & 1 & 1 & 1 & 1 & 1 & 1 & 1 & 1 & high \\
\hline Erculj 2009 & 1 & 1 & 1 & 1 & 1 & 1 & 1 & 1 & 1 & 1 & high \\
\hline Erculj 2011 & 1 & 1 & 1 & 1 & 1 & 1 & 1 & 1 & 1 & 1 & high \\
\hline Fernández-Leo 2020 & 1 & 1 & 1 & 1 & 1 & 1 & 1 & 1 & 1 & 1 & high \\
\hline Fort-Vanmeerhaeghe 2016 & 1 & 1 & 1 & 1 & 1 & 1 & 1 & 1 & 1 & $?$ & high \\
\hline Garcia-Gil 2018 & 1 & 1 & 1 & 1 & 1 & 1 & 1 & 1 & 1 & 1 & high \\
\hline Guimaraes 2019 & 1 & 1 & 1 & 1 & 1 & 1 & 1 & 1 & 1 & 1 & high \\
\hline Haugen 2019 & 1 & 1 & 1 & 1 & 1 & 1 & 1 & 1 & 1 & 1 & high \\
\hline Heishman 2020 & 1 & 1 & 1 & 1 & 1 & 1 & 0 & 1 & 1 & 1 & high \\
\hline Jakovljevic 2011 & 1 & 1 & 1 & 1 & 1 & 1 & 1 & 1 & 1 & 1 & high \\
\hline Jakovljevic 2015 & 1 & 1 & 1 & 1 & 1 & 1 & 1 & 1 & 1 & 1 & high \\
\hline Köklü 2011 & 1 & 1 & 1 & 1 & 1 & 1 & 0 & $?$ & $?$ & 1 & med. \\
\hline Legg 2017 & 1 & 1 & 1 & 1 & 1 & 1 & 1 & 1 & 1 & 1 & high \\
\hline Lockie 2014 & 1 & 1 & 1 & $?$ & 1 & 1 & 1 & 1 & 1 & 1 & high \\
\hline Manuel Clemente 2019 & 1 & 1 & 1 & 1 & 1 & 1 & 1 & 1 & 1 & 1 & high \\
\hline Mtsweni 2017 & $?$ & 1 & 1 & 1 & 1 & $?$ & 1 & 1 & 1 & $?$ & high \\
\hline Palheta 2019 & 1 & 1 & 1 & 1 & 1 & 1 & $?$ & 1 & 1 & 1 & high \\
\hline Pehar 2017 & 1 & 1 & 1 & 1 & 1 & 1 & 1 & 1 & 1 & 1 & high \\
\hline Pojskic 2015 & 1 & 1 & 1 & 1 & 1 & 1 & 1 & 1 & 1 & 1 & high \\
\hline Portes 2019 & 1 & 1 & 1 & 1 & 1 & 1 & $?$ & 1 & 1 & 1 & high \\
\hline Ramos 2020 & 1 & 1 & 1 & 1 & 1 & 1 & 1 & 1 & 1 & 1 & high \\
\hline Ramos 2019 & 1 & 1 & 1 & 1 & 1 & 1 & 1 & 1 & 1 & 1 & high \\
\hline Román 2019 & 1 & 1 & 1 & $?$ & 1 & 1 & 1 & 1 & 1 & 1 & high \\
\hline Sarvestan 2019 & 1 & 1 & 1 & 1 & 1 & 1 & $?$ & $?$ & $?$ & $?$ & med. \\
\hline Scanlan 2014 & 1 & 1 & 1 & 1 & 1 & 1 & 1 & $?$ & 1 & $?$ & high \\
\hline Sekulic 2017 & 1 & 1 & 1 & 1 & 1 & 1 & 1 & 1 & 1 & 1 & high \\
\hline Stojanovic 2019 & 1 & 1 & 1 & 1 & 1 & 1 & 1 & 1 & 1 & 1 & high \\
\hline Strumbelj 2015 & 1 & 1 & 1 & 1 & 1 & 1 & 1 & 1 & 1 & 1 & high \\
\hline Torres-Unda 2013 & 1 & 1 & 1 & 1 & 1 & 1 & 1 & 1 & 1 & 1 & high \\
\hline Wierike 2015 & 1 & 1 & 1 & 1 & 1 & 1 & 1 & 1 & 1 & 1 & high \\
\hline
\end{tabular}

Figure 2. Results of quality assessment for each included article. 1: acceptable; ?: unclear risk of bias; 0: questionable. 
Table 1. Differences in test results, athletic abilities, and body parameters between players in different positions.

\begin{tabular}{|c|c|c|c|}
\hline Athletic Abilities & Guards & Forwards & Centers \\
\hline Anaerobic capacity & higher $\mathrm{VO}_{\text {peak }}[1-4]$ & & \\
\hline Aerobic capacity & & iminative factor [5] & \\
\hline Speed & $\begin{array}{l}\text { faster, higher top } \\
\text { speed }[3,23,24]\end{array}$ & & \\
\hline Agility* & quicker [2-4,24-28] & & \\
\hline Strength & & & stronger $[5,23-25,27,29]$ \\
\hline Normalized strength & & fference $[3,23,30]$ & \\
\hline Jumping ability & best $r$ & & \\
\hline Body parameters & Guards & Forwards & Centers \\
\hline Anthropometrics * & & & $\begin{array}{c}\text { taller, more massive } \\
{[1,3-5,18,23-25,27,31,33]}\end{array}$ \\
\hline
\end{tabular}

* important discriminative factor of the basketball player positions.

\subsubsection{Anthropometry}

There is a broad consensus about the anthropometric differences between basketball players playing at different positions, i.e., forwards and centers are significantly taller than guards, and centers are significantly more massive than the other players [1,3-5,18,23-25,27,31,33]. Legg et al. [31] suggested that players can be categorized into positions based on their anthropometric attributes, with centers and forwards being taller and more massive than guards. For a better comparison between players of different body sizes, Palheta et al. [20] suggested using allometric scaling instead of the standard ratios. They found that allometric scaling models have the potential to explain the body dimensions' influence on performance successfully. Thus, the future performance of the player could be also predicted more efficiently [20].

\subsubsection{Aerobic and Anaerobic Capacity}

It has been confirmed that point guards and shooting guards have a higher top speed and a corresponding peak oxygen uptake $\left(\mathrm{VO} 2_{\text {peak }}\right)$ at the anaerobic threshold as compared with forwards and centers [1]. Therefore, it is suggested to be a suitable variable to distinguish basketball players playing at different positions [2-4]. On the other hand, no differences were found regarding the values of aerobic endurance during a shuttle running test (30 s running, $15 \mathrm{~s}$ recovery) [5], indicating that aerobic endurance may not be considered as a discriminative factor of playing position.

\subsubsection{Speed and Agility}

Many studies aimed to determine whether the sprint performance of basketball players at different positions may differ. Some experts found significant differences in sprinting performance between playing positions [3,23-26], while others did not $[1,5]$. Scanlan et al. [24] tested twelve adult male basketball players competing in the Queensland Basketball League and found that backcourt vs. frontcourt players likely possess a superior sprinting ability. Erčulj et al. [23] reported similar results for female players, i.e., a significant difference was found in sprint performance at different playing positions, most probably due to the differences in body height and body weight that significantly influence the speed of acceleration. This is in line with the study results from Boone et al. [3]: data from 144 elite basketball players support the idea that taller and heavier centers are significantly slower in incremental running, $10 \mathrm{~m}$ sprint, and $5 \times 10 \mathrm{~m}$ sprint tests.

A considerable amount of literature has proved that smaller players perform better not only in sprint but also in agility tests $[2,3,24-26]$. At the amateur level, it appeared that 
guards are responsible for accelerating the rhythm of the game by having significantly more effective on-court time $\left(p<0.01, \mathrm{E}^{2} \mathrm{R}=0.05\right)$ and taking more steps $/ \mathrm{min}\left(p<0.01, \mathrm{E}^{2}{ }_{\mathrm{R}}=0.28\right)$, while centers are mostly involved in competitive actions such as impacts $/ \mathrm{min}(p<0.01$, $\left.\mathrm{E}^{2}{ }_{\mathrm{R}}=0.20\right)$ or jumps $/ \mathrm{min}\left(p<0.01, \mathrm{E}^{2} \mathrm{R}=0.33\right)$ and have better technical performance [34].

Some $[4,27,28]$, but not all [1] studies supported the idea that agility tests might be useful indicators for determining the most appropriate playing position of the athlete. Experts emphasized the importance of agility skills during position specialization $[4,24,27,28,35]$, including the Agility T-test [4], or the basketball-specific open-skill nonplanned [24] and pre-planned [28,35] agility tests. The Lane Agility Drill test is one of the most sensitive tests to identify position-specific disparities in the change of direction (COD) performance [27]. Even though frontcourt players seem to possess a quicker COD speed than backcourt players, body height and body mass had a smaller influence on the speed of acyclic and agility movements [23]. In contrast, Jakovljevic et al. [1] found no differences between the inner and outer players' $20 \mathrm{~m}$ run test (acceleration based on $5 \mathrm{~m}$ and $10 \mathrm{~m}$ split times) and agility test results.

\subsubsection{Strength}

Several researchers reported that even though the body sizes, and thus the absolute strength may be significantly different between players playing at different playing positions $[5,24,25,27]$, the normalized strength values are broadly similar $[3,23,30]$. According to Ferioli et al. [29], the strength and power characteristics can discriminate guards from forwards and centers among male basketball players. This statement may be correct for tests that are influenced by anthropometric parameters. For example, in power tests of the throwing type, such as basketball throw and medicine ball throw, Erčulj et al. [23] found that smaller guards scored the lowest results. In contrast, the comparatively taller forwards and centers scored higher.

In the case of the back squat, vertical jumps, isokinetic peak torque, and absolute power reached on the $30 \mathrm{~s}$ Wingate Anaerobic test, the tendency between playing positions is not clear. Testing female basketball players, Delextrat et al. [30] and Jakovljevic et al. [36] did not find any difference amongst guards, forwards, and centers in the peak torques produced in isokinetic strength tests. In contrast, Boone et al. [3] showed that centers displayed significantly lower absolute performance than other players.

\subsubsection{Jumping Ability}

Most studies reported that guards and forwards achieved the best results of jumping performance, which were, on average, almost on par with centers [23,31,32]. Legg et al. [31] found that guards and forwards exhibited higher peak velocities in their CMJ, suggesting that this could be an essential performance factor for these positions. Even though the reliability of the running jump was lower (ICC $=0.79$ ) than the reliability of CMJ (ICC $=0.81$ ), the running jump showed a strong and significant difference between playing positions. Therefore, running vertical jumps and repeated jumping capacity can be used as valid measures of position-specific jumping ability in basketball [32].

\subsection{Differences between Playing Levels}

Modern basketball requires a player with a highly complex skillset. They must be quick, strong, energetic, well-trained; furthermore, they also have to make smart and quick decisions [19]. This section aims to expose which skills can distinguish the players from different playing or competitive levels and which tests can be appropriate to detect such differences. Table 2 summarizes studies that found $(p<0.05)$ or failed to identify $(p \geq 0.05)$ differences between players in different playing levels in test results, athletic abilities, and body parameters. 
Table 2. Differences in test results, athletic abilities, and body parameters between players in different playing levels.

\begin{tabular}{|c|c|c|}
\hline Test Types & $\begin{array}{c}\text { Significant Differences Were } \\
\text { Found }(p<0.05)\end{array}$ & $\begin{array}{c}\text { Significant Differences Were } \\
\text { Not Found }(p \geq 0.05)\end{array}$ \\
\hline Jump test & {$[22,37,38]^{*},[39]^{\wedge},[40]$} & {$[23,38]^{* *}$} \\
\hline Sprint tests & {$[38]^{*}[39] \wedge,[40]$} & {$[22,23,37,38]^{*}$} \\
\hline Medicine throw & {$[38]^{*},[39]^{\wedge},[41]$} & {$[23,38]^{*}$} \\
\hline Basketball throw & {$[39]^{\wedge},[41]$} & \\
\hline Suicide run & & [37] \\
\hline Athletic abilities & $p<0.05$ & $p \geq 0.05$ \\
\hline Planned agility & {$[23,37,39]^{\wedge},[40]$} & [22] \\
\hline Reactive agility & {$[22,28,35]$} & \\
\hline Strength & {$[23,29,37,39] \wedge,[42]$} & \\
\hline Flexibility & [23] & \\
\hline Explosive power & [43] & \\
\hline Aerobic capacity & {$[23]^{\wedge},[39,40]$} & \\
\hline Body parameters & $p<0.05$ & $p \geq 0.05$ \\
\hline Anthropometrics & {$[22,23,28,29,37,39] \wedge,[40,41,44]$} & \\
\hline Maturity status & {$[39,40,44]$} & \\
\hline
\end{tabular}

\subsubsection{Anthropometry and Maturity}

Most studies agreed that anthropometric parameters are different amongst playing levels $[28,29,33,37-41,44,45]$. Maturational status appeared to be the critical variable of selection for the Portuguese U-16 national team, i.e., post-pubertal players were more likely to be selected into the U16 national team than pre-pubertal ones $[39,44]$. This might be in line with the observation that around puberty, the success of the basketball players associated with maturity and chronological age [40]. Erčulj et al. [38] tested 65 female basketball players who played in a U16 European Championships in three different divisions (A, B, C). They found that the physical abilities of players from divisions A and B were relatively homogeneous, whereas players from division $C$ underperformed in all tests. This account may explain the importance of maturity status during selection among adolescent players.

\subsubsection{Aerobic and Anaerobic Capacity}

Delextrat et al. [37] examined male basketball players from two different levels. They concluded that the elite-level players were significantly better in tests of agility, strength, and reactive power but not in the results of sprinting skills and aerobic endurance. They underline the importance of anaerobic power in basketball, while anaerobic capacity does not seem to be an essential aspect of success. Mtsweni et al. [33] had similar results in most cases. However, they had a surprising finding regarding aerobic endurance, where provincial-level players performed significantly better than the national team players in the aerobic fitness test.

\subsubsection{Agility}

In contrast to the aerobic and anaerobic capacities, Lockie et al. [45] could not find significant differences between playing levels either in values of the planned-agility tests or in the results of the $10 \mathrm{~m}$ sprint test. Nevertheless, their data support the idea that 
results of reactive agility tests might be a useful tool to discriminate between playing levels. This is in line with the studies from Sekulic et al. [35] and Wierike et al. [28] so that reactive vs. pre-planned agility tests appear to be more valid for determining differences between basketball players from two competitive levels. Ramos et al. [39] concluded that stature and abdominal resistance were more important selection criteria between young basketball players as compared to the results of $20 \mathrm{~m}$ speed test, Agility $t$-test, squat jump (SJ), CMJ, 2 kg medicine ball throw, handgrip strength, $60 \mathrm{~s}$ sit-up test or Yo-Yo intermittent recovery test. Nevertheless, agility performance becomes a more dominantly discriminative attribute as they are getting older. Ferioli et al. [29] found that the ability to sustain highintensity intermittent efforts and strength/power characteristics can differentiate between competitive levels. Comparing Italian basketball players from four different divisions, Ferioli et al. [42] concluded that lower-level players showed greater amounts of muscle fatigue during the repeated COD run. At the same time, players of higher competitive levels demonstrated better muscle peak torque of knee extensor muscles measured during the multi-stage changes of direction exercise.

\subsubsection{Explosive Power}

A review from Aksović et al. [43] suggested the explosive power to be a determining skill of professional basketball players and one of the most important factors for achieving top results. As a test of explosive power, Sarvestan et al. [22] found that elite basketball players performed the CMJ significantly faster than collegiate players and produced higher measures of force, velocity, and, consequently, power, most probably due to the lower body mass of collegiate players. Examining body mass normalized parameters, they established that collegiate players produced higher amounts of relative force and power. However, elite players performed the $\mathrm{CMJ}$ in a shorter period of time with higher velocities.

To summarize, we can establish that maturity status is the most decisive factor for young players (Table 2). From U18 and up, agility (especially reactive agility) and reactive power are the specific discriminant attributes for performance in basketball apart from stature (height and size). We should note that sprint performance did not appear to be a useful discriminative factor during selection, neither between youth nor between adult players.

\subsection{Differences between Match Performance}

Another interesting question is whether match statistics are associated with the field test results. We found only a few articles in the literature from the last 12 years investigating this question, providing a fruitful and relevant research area for future studies. Correlations between different skills and match performance are summarized in Table 3. Drinkwater et al. [13] reported that the relationships between fitness test results and playing ability are unclear. They found that most researchers compared only a single measured test protocol with basketball performance instead of analyzing data collected repeatedly on an individual over time. According to Arede et al. [46], besides the physical characteristic, the game-related statistics were the factors that influence the choice of the starter players the most during the U16 European Championship. 
Table 3. Correlations between test results of skills and match statistics.

\begin{tabular}{|c|c|c|c|c|c|c|c|c|c|}
\hline & $\begin{array}{l}\text { Anaerobic } \\
\text { Capacity }\end{array}$ & Aerobic Capacity & Agility & Jump & Speed & Repeated Sprint & Strength & Dribbling & $\begin{array}{c}\text { Anthropometrics, } \\
\text { Age }\end{array}$ \\
\hline $\begin{array}{l}\text { match } \\
\text { performance } \\
\text { (PIR/min) }\end{array}$ & & & T-test * $[47]$ & & & & & & $\begin{array}{l}\text { height }{ }^{* *}, \mathrm{BM}^{* *}, \\
\text { AS }^{*}, \text { age }^{* *}[47]\end{array}$ \\
\hline assists & Line-Drill * [48] & Yo-Yo test ${ }^{* *}[48]$ & T-test ${ }^{* *}[48]$ & $\begin{array}{l}\text { Abalakov- } \\
\text { test* }{ }^{*}[48]\end{array}$ & $\begin{array}{l}3 / 4 \text { sprint } \\
\text { test } * *[48]\end{array}$ & RSA test ${ }^{* *}[48]$ & & & $\operatorname{age}^{* *}[48]$ \\
\hline steal & Line-Drill * [48] & Yo-Yo test ** $[48]$ & T-test * $[48]$ & & $\begin{array}{l}3 / 4 \text { sprint } \\
\text { test * }[48]\end{array}$ & RSA test ${ }^{* *}[48]$ & & & \\
\hline $\begin{array}{l}\text { high intensity } \\
\text { shuffling during } \\
\text { the game }\end{array}$ & & & T-test $* *[49]$ & & & & & & \\
\hline $\begin{array}{l}\text { high intensity } \\
\text { performance } \\
\text { during the game }\end{array}$ & $\begin{array}{l}\text { shuttle-run } \\
\text { test *[49] }\end{array}$ & $\begin{array}{l}20 \mathrm{~m} \text { shuttle } \\
\text { test * [49] }\end{array}$ & & & & & & & \\
\hline playing time & & & & & & & $\begin{array}{c}1 \text { RM bench } \\
\text { press *, } \\
1 \text { RM back } \\
\text { squat * }[50]\end{array}$ & & \\
\hline $\begin{array}{l}\text { final standing in a } \\
\text { championship }\end{array}$ & & & T-test ${ }^{* *}[51]$ & & $20 \mathrm{~m}$ sprint ${ }^{* *}[51]$ & & $\begin{array}{c}2 \mathrm{~kg} \text { Medicine Ball } \\
\text { Throw * }\end{array}$ & $\begin{array}{l}\text { dribbling } \\
\text { test * }[47]\end{array}$ & $\mathrm{BF} \% *[51]$ \\
\hline team success & & & & & 20 m sprint ${ }^{*}[38]$ & & $\begin{array}{c}2 \mathrm{~kg} \text { Medicine Ball } \\
\text { Throw * }\end{array}$ & $\begin{array}{c}6 \times 5 \mathrm{~m} \\
\text { dribbling *[38] }\end{array}$ & height * [38] \\
\hline
\end{tabular}

1 RM, 1 Repetition Maximum; AS, Arm Span; BM, Body Mass; BF\%, Body Fat Percentage; PIR, Performance Index Rating; RSA, Repeated Sprint Ability. * $p<0.05,{ }^{* *} p<0.01$. 


\subsubsection{Anthropometry}

As mentioned previously, Erčulj et al. [38] compared different divisions in the U16 European Championship. Their results showed that players from more successful teams were taller and had more extensive training experience. This is in line with the results from Manuel Clement et al. [52], who found significant correlations between anthropometry and technical performance during small-sided games. Furthermore, Guimarães et al. [53] also found that the physical performance not only depended on maturity status but was also being influenced by the years of training among 11-14 year old male basketball players. Interestingly, Ramos et al. [51] had contrary results; they found no differences for maturity status, anthropometric and physiological parameters amongst teams with different final standing in the championship, neither in men nor in women.

\subsubsection{Aerobic and Anaerobic Capacity}

While Abdelkrim et al. [49] found that aerobic performance (i.e., 20 m shuttle test/beep test) moderately but significantly associated with the high-intensity anaerobic performance during the match, Fort-Vanmeerhaeghe et al. [48] detected two performance variables, i.e., steals and assists per game, that correlated significantly with anaerobic power, repeated sprint ability and aerobic power (all $p \leq 0.05$ ).

\subsubsection{Speed and Agility}

Results from 18 Tunisian elite junior basketball players showed a significant negative correlation between T-test performance and the distance covered at high-intensity shuffling during the game [47]. Similar results were reported among Spanish women basketball players so that the time in the Agility T-test negatively correlated with the Performance Index Rating (PIR) per min $(p<0.05)$. Concurring results were reported by Fort-Vanmeerhaeghe et al. [48] and Ramos et al. [51], i.e., agility positively influenced the match performance.

\subsubsection{Strength}

In the National Collegiate Athletic Association (NCAA), significant correlations were observed between playing time and predicted one repetition maximum (1 RM) bench press and 1 RM back squat [50]. Ramos et al. [51] also found differences in strength abilities among teams with different final standing in the championship.

\subsubsection{Jumping Ability}

Fort-Vanmeerhaeghe et al. [48] detected that steals (squat jump (SJ): $p=0.274, \mathrm{CMJ}$ : $p=0.262$ ) and assists per game (SJ: $p=0.443, \mathrm{CMJ}: p=0.436$ ) correlated significantly with jumping performance.

\subsubsection{Dribbling Ability}

Garcia-Gil et al. [47] and Erčulj et al. [38] identified that higher-level motor potential, especially in terms of particular basketball motor tasks with the ball, is one of the most influencing factors of in-match success.

\subsubsection{Model for Multiple Attributes}

Garcia-Gil et al. [47] examined several anthropometric datasets and physical tests connected with match performance and created a model for predicting the match performance. In their model, attributes such as age, height and contracted arm perimeter had a positive-, while time in the Agility T-test and the sum of skinfold thickness had a negative influencing factor.

To summarize, based on our literature search, agility is the most influencing skill of the basketball match performance, even in the youth (Table 3). This is surprising, because as we presented in the previous section, for this age group, the most influencing factor during selection was maturity status, while physical parameters (such as agility, speed, strength) appeared to be unimportant. 


\section{Discussion}

The purpose of the present systematic review was to summarize the abilities and features of basketball field-testing studies that can support distinguishing between playing positions and playing levels. We also tried to answer whether the results of such field tests may correlate with match statistics. Based on 39 studies, it could be supported that the agility, speed, and jumping test values seem to be crucial measures for basketball players. Anthropometry appeared to be the strongest discriminative factor between basketball positions; therefore, these values need to be significantly considered during selection. Moreover, maturity status is also an important influencing factor for U-18 teams. In general, we found that successful players can be identified by their nonplanned agility and reactive power, considering that these factors affect match outcomes the most at the same competitive level.

Even though it is not recommended to pick a playing position too early, we tried to summarize the abilities and features of basketball field-testing studies that can support distinguishing between playing positions (Table 1), which may help to find the most appropriate positions for a player during talent identification and development. In line with our expectations, the anthropometric values showed to be the strongest discriminative factor between basketball players playing at different positions. The agility, speed and jumping test values seem to be significantly defining features of playing position. Regarding the agility tests, the Lane Agility Drill test appeared to be the most sensitive test to identify position-specific disparities [27]. Nevertheless, most of the experts agreed that the differences between the values of agility, speed and jump test of players from different positions mostly caused by the differences in their anthropometric characteristics. Court strength tests appeared to be inappropriate discriminative factors. Nevertheless, it is also advisable to use normalized values during strength tests. Moreover, values of only anaerobic but not aerobic endurance are significantly different between players playing at different positions. Consequently, agility, speed and anaerobic endurance should be tested during post specialization with careful consideration of the anthropometric data. Moreover, the training process should be also individualized.

During scouting, trainers select players for a team. Apart from the basketball-specific skills, scouts and experts usually pay attention to the athletic performance as well. We researched which parameters could facilitate a useful distinction amongst players regarding playing level (Table 2) and regarding match performance (Table 3). Our results could help scientists, scouts and trainers to choose these skills and abilities, which actually and effectively distinguish players.

Regarding playing levels, interestingly, in many cases, the conditional ability of the players is not different between the top two playing levels (Table 2). We found that maturity status is the most defining factor at young ages. From U18 and up, the specific attributes are agility (especially reactive agility), strength and reactive power apart from stature. This result highlights the usefulness and applicability of the jump tests and reactive agility tests. Our results highlight that the players from top levels are stronger and more agile, which fulfill the requirements of the modern, accelerated basketball. The values of one-direction sprint tests and aerobic endurance appeared to be non-significant during selection neither between youth nor between adult players.

Finally, we searched which physical skills are the determinative factors of the match performance (Table 3). The literature review suggests that this topic has not yet been wellexplored. Agility is the most influencing skill regarding basketball match performance; however, strength skills are also a determining factor. We found that the results of the Agility T-test are a meaningful measure among basketball players. To determine the players' on-field performance, experts should use basketball-specific tests, which consist of special technical elements such as dribbling and throwing. Interestingly, the body structure is not influencing the final result of the match at the same playing level in the youth. These results reflect well the characteristics of modern, fast, and varied basketball. 
Regarding the limitations of this current review, limitations arise from the wide scope of the topic itself. As discussed, numerous athletic abilities are being tested concerning basketball. Efforts had been made at the material identification step to search repeatedly both with broader (e.g., "basketball AND physical assessment") and more specific (e.g., "basketball AND agility") search terms about the topic. Nevertheless, the results summarized in Tables 1-3 are limited in that more studies could have been identified with ability-, or test-specific searching.

\section{Conclusions}

The selection and transfer in professional and amateur basketball are very complex subjects for all age groups. In addition to the basketball-specific skills, physical performance is also essential. In this systematic review, we aimed to determine which physical factors differentiate basketball players the most efficiently at different positions and playing levels and whether test results correlate with match statistics. We found that during the selection of players, anthropometry is very important; however, under the age of 18, experts should take the maturity status into account as well. In addition to the structure of the body, the non-planned agility and reactive power have the potential to identify the successful players. At the same competitive level, agility and strength skills are the most influencing factors of the match outcome.

Supplementary Materials: The following are available online at https://www.mdpi.com/article/10 .3390/app11104340/s1, Table S1: The collected data from the literature review.

Author Contributions: Conceptualization, R.M.K., B.P. and A.G.-P.; methodology, R.M.K. and B.P.; software, A.G.-P.; validation, R.M.K., B.P. and A.G.-P.; formal analysis, A.G.-P., B.P. and J.N.; investigation, A.G.-P., A.C., B.P. and J.N.; resources, R.M.K.; data curation, A.G.-P., A.C., B.P. and J.N.; writing—original draft preparation, A.G.-P.; writing—review and editing, B.P., R.M.K., J.N. and R.N.; visualization, B.P. and J.N.; supervision, R.M.K. and R.N.; project administration, R.M.K.; funding acquisition, R.M.K. All authors have read and agreed to the published version of the manuscript.

Funding: This research was supported by the Hungarian Scientific Research Fund of the National Research, Development, and Innovation Office (NRDI) (Grant No OTKA K 115894). The research reported in this paper and carried out at BME has been supported by the NRDI Fund TKP2020 IES (Grant No. BME-IE-BIO) based on the charter of bolster issued by the NRDI Office under the auspices of the Ministry for Innovation and Technology, Hungary.

Institutional Review Board Statement: Not applicable.

Informed Consent Statement: Not applicable.

Data Availability Statement: The data presented in this study are available in Supplementary material 1.

Conflicts of Interest: The authors declare no conflict of interest. The funders had no role in the design of the study; in the collection, analyses or interpretation of data; in the writing of the manuscript, or in the decision to publish the results.

\section{References}

1. Jakovljevic, S.; Karaleji, M.; Pajj, Z.; Mandi, R. Acceleration and speed of change of direction and the way of movement of quality basketball players. Fizička Kult. 2011, 65, 16-23. [CrossRef]

2. Pojskic, H.; Separovic, V.; Uzicanin, E.; Muratovic, M.; Mackovic, S. Positional Role Differences in the Aerobic and Anaerobic Power of Elite Basketball Players. J. Hum. Kinet 2015, 49, 219-227. [CrossRef] [PubMed]

3. Boone, J.; Bourgois, J. Morphological and physiological profile of elite basketball players in Belgian. Int. J. Sports Physiol. Perform. 2013, 8, 630-638. [CrossRef] [PubMed]

4. Koklu, Y.; Alemdaroglu, U.; Kocak, F.U.; Erol, A.E.; Findikoglu, G. Comparison of chosen physical fitness characteristics of Turkish professional basketball players by division and playing position. J. Hum. Kinet 2011, 30, 99-106. [CrossRef]

5. Strumbelj, B.; Vuckovic, G.; Jakovljevic, S.; Milanovic, Z.; James, N.; Erculj, F. Graded shuttle run performance by playing positions in elite female basketball. J. Strength Cond. Res. 2015, 29, 793-799. [CrossRef] 
6. Mackała, K.; Kurzaj, M.; Okrzymowska, P.; Stodółka, J.; Coh, M.; Rożek-Piechura, K. The Effect of Respiratory Muscle Training on the Pulmonary Function, Lung Ventilation, and Endurance Performance of Young Soccer Players. Int. J. Environ. Res. Public Health 2019, 17, 234. [CrossRef]

7. Alvero-Cruz, J.R.; Giráldez García, M.A.; Carnero, E.A. Reliability and accuracy of Cooper's test in male long distance runners. Rev. Andaluza. Med. Deporte 2017, 10, 60-63. [CrossRef]

8. Franchini, E.; Nunes, A.V.; Moraes, J.; Del Vecchio, F.B. Physical Fitness and Anthropometrical Profile of the Brazilian Male Judo Team. J. Physiol. Anthropol. 2007, 26, 59-67. [CrossRef]

9. Taskiran, C. Comparison of the Physical and Physiological Capacities of Elite Turkish Wrestlers and the Wrestlers of the U.S. National Wrestling Team. Int. J. Wrestl. Sci. 2014, 4, 11-14. [CrossRef]

10. Brini, S.; Ben Abderrahman, A.; Boullosa, D.; Hackney, A.C.; Zagatto, A.M.; Castagna, C.; Bouassida, A.; Granacher, U.; Zouhal, H. Effects of a 12-Week Change-of-Direction Sprints Training Program on Selected Physical and Physiological Parameters in Professional Basketball Male Players. Int. J. Environ. Res. Publ. Heatlh 2020, 17, 8214. [CrossRef]

11. DeWeese, B.H.; Nimphius, S. Program design and technique for speed and agility training. In Essentials of Strength Training and Conditioning; Haff, G.G., Triplett, N.T., Eds.; Human Kinetics Publishers: Champaign, IL, USA, 2018.

12. Conte, D.; Favero, T.G.; Lupo, C.; Francioni, F.M.; Capranica, L.; Tessitore, A. Time-motion analysis of Italian elite women's basketball games: Individual and team analyses. J. Strength Cond. Res. 2015, 29, 144-150. [CrossRef] [PubMed]

13. Drinkwater, E.J. Fitness and anthropometric testing in basketball players. In Handbook of Anthropometry: Physical Measures of Human Form in Health and Disease; P'reedy, V.R., Ed.; Springer: Berlin/Heidelberg, Germany, 2012; pp. 1837-1856.

14. Reina Roman, M.; Garcia-Rubio, J.; Feu, S.; Ibanez, S.J. Training and Competition Load Monitoring and Analysis of Women's Amateur Basketball by Playing Position: Approach Study. Front. Psychol. 2018, 9, 2689. [CrossRef] [PubMed]

15. Heishman, A.D.; Daub, B.D.; Miller, R.M.; Freitas, E.D.S.; Bemben, M.G. Monitoring External Training Loads and Neuromuscular Performance for Division I Basketball Players over the Pre-season. J. Sports Sci. Med. 2020, 19, 204-212. [CrossRef]

16. Spiteri, T.; Binetti, M.; Scanlan, A.T.; Dalbo, V.J.; Dolci, F.; Specos, C. Physical Determinants of Division 1 Collegiate Basketball, Women's National Basketball League, and Women's National Basketball Association Athletes: With Reference to Lower-Body Sidedness. J. Strength Cond. Res. 2019, 33, 159-166. [CrossRef] [PubMed]

17. Strumbelj, E.; Erculj, F. Analysis of experts' quantitative assessment of adolescent basketball players and the role of anthropometric and physiological attributes. J. Hum. Kinet. 2014, 42, 267-276. [CrossRef]

18. Drinkwater, E.J.; Pyne, D.B.; McKenna, M.J. Design and interpretation of anthropometric and fitness testing of basketball players. Sports Med. 2008, 38, 565-578. [CrossRef] [PubMed]

19. Begu, B.; Kryeziu, A.R.; Bahtiri, A. The influence of anthropometric variables in agility abilities of young basketball players. Sport Sci. 2018, 11, 57-60.

20. Palheta, C.E.; Milan, F.J.; Soares, A.L.; Miguel, C.G.; Collet, C.; Mendes, F.G.; Milistetd, M.; Carvalho, H.M. Allometric Scaling of Agility and Power Performance in Basketball Players. Rev. Psicol. Deporte 2019, 28, 8.

21. Portes, R.; Navarro, R.M.; Sosa Marín, C.; Trapero, J.J.; Jiménez Saiz, S.L. Monitoring and Interpreting External Load in Basketball: A Narrative Review. Rev. Psicol. Deporte 2019, 28, 0119-0131.

22. Sarvestan, J.; Cheraghi, M.; Shirzad, E.; Svoboda, Z. Experience Related Impacts on Jump Performance of Elite and Collegiate Basketball Players; Investigation on Force-Time Curvature Variables. Sport Mont. 2019, 17, 23-28. [CrossRef]

23. Erculj, F.; Blas, M.; Coh, M.; Bracic, M. Differences in motor abilities of various types of European young elite female basketball players. Kinesiology 2009, 41, 203-211.

24. Scanlan, A.T.; Tucker, P.S.; Dalbo, V.J. A comparison of linear speed, closed-skill agility, and open-skill agility qualities between backcourt and frontcourt adult semiprofessional male basketball players. J. Strength Cond. Res. 2014, 28, $1319-1327$. [CrossRef] [PubMed]

25. Erculj, F.; Jakovljevi, S. The level of speed and agility of different types of female basketball players. Facta Univ. Ser. Phys. Educ. Sport 2011, 9, 283-293.

26. Haugen, T.A.; Breitschädel, F.; Seiler, S. Sprint Mechanical Properties in Handball and Basketball Players. Int. J. Sports Physiol. Perform. 2019, 1-7. [CrossRef] [PubMed]

27. Stojanovic, E.; Aksovic, N.; Stojiljkovic, N.; Stankovic, R.; Scanlan, A.T.; Milanovic, Z. Reliability, Usefulness, and Factorial Validity of Change-of-direction Speed Tests in Adolescent Basketball Players. J. Strength Cond. Res. 2019, 33, $3162-3173$. [CrossRef] [PubMed]

28. Wierike, S.C.M.T.; Tromp, E.J.Y.; Meerhoff, L.A.; Coelho-e-Silva, M.J.; Elferink-Gemser, M.T.; Visscher, C. Reproducibility and validity of the STARtest: A test to monitor the change-of-direction speed and ball control of youth basketball players: Running head: Reproducibility and validity of the STARtest. Ann. Res. Sport Phys. Act. 2015. Available online: https://www.researchgate.net/profile/Rens_Meerhoff/publication/299536624_Reproducibility_and_validity_of_the_ STARtest_a_test_to_monitor_the_change-of-direction_speed_and_ball_control_of_youth_basketball_players_Running_head_ reproducibility_and_validity_of_the_STARtest/links/570b499208ae8883a1fc3f54.pdf (accessed on 12 July 2020).

29. Ferioli, D.; Rampinini, E.; Bosio, A.; La Torre, A.; Azzolini, M.; Coutts, A.J. The physical profile of adult male basketball players: Differences between competitive levels and playing positions. J. Sports Sci 2018, 36, 2567-2574. [CrossRef] [PubMed]

30. Delextrat, A.; Cohen, D. Strength, power, speed, and agility of women basketball players according to playing position. J. Strength Cond. Res. 2009, 23, 1974-1981. [CrossRef] 
31. Legg, J.S. Physiological Profile and Variability of Jump Kinetics in National Level Female Basketball Players. Ph.D. Thesis, University of Canberra, Canberra, Australia, 2017.

32. Pehar, M.; Sekulic, D.; Sisic, N.; Spasic, M.; Uljevic, O.; Krolo, A.; Milanovic, Z.; Sattler, T. Evaluation of different jumping tests in defining position-specific and performance-level differences in high level basketball players. Biol. Sport 2017, 34, 263-272. [CrossRef] [PubMed]

33. Mtsweni, L.B.; West, S.J.; Taliep, M.S. Anthropometric and physical fitness characteristics of female basketball players in South Africa. South Afr. J. Res. Sport Physical. Educ. Recreat. 2017, 39, 93-103.

34. Fernández-Leo, A.; Gómez-Carmona, C.D.; García-Rubio, J.; Ibáñez, S.J. Influence of Contextual Variables on Physical and Technical Performance in Male Amateur Basketball: A Case Study. Int. J. Environ. Res. Public Health 2020, 17, 1193. [CrossRef]

35. Sekulic, D.; Pehar, M.; Krolo, A.; Spasic, M.; Uljevic, O.; Calleja-González, J.; Sattler, T. Evaluation of Basketball-Specific Agility: Applicability of Pre-planned and Nonplanned Agility Performances for Differentiating Playing Positions and Playing Levels. J. Strength Cond. Res. 2017, 31, 2278-2288. [CrossRef] [PubMed]

36. Jakovljevic, S.; Karalejic, M.S.; Pajic, Z.B.; Jankovic, N.; Erculj, F. Relationship between 1RM back squat test results and explosive movements in professional basketball players. Auc Kinanthropologica 2015, 51, 41-50. [CrossRef]

37. Delextrat, A.; Cohen, D. Physiological testing of basketball players: Toward a standard evaluation of anaerobic fitness. J. Strength Cond Res. 2008, 22, 1066-1072. [CrossRef]

38. Erculj, F.; Blas, M.; Bracic, M. Physical demands on young elite European female basketball players with special reference to speed, agility, explosive strength, and take-off power. J. Strength Cond. Res. 2010, 24, 2970-2978. [CrossRef]

39. Ramos, S.; Volossovitch, A.; Ferreira, A.P.; Fragoso, I.; Massuça, L. Differences in maturity, morphological and physical attributes between players selected to the primary and secondary teams of a Portuguese Basketball elite academy. J. Sports Sci. 2019, 37, 1681-1689. [CrossRef]

40. Torres-Unda, J.; Zarrazquin, I.; Gil, J.; Ruiz, F.; Irazusta, A.; Kortajarena, M.; Seco, J.; Irazusta, J. Anthropometric, physiological and maturational characteristics in selected elite and non-elite male adolescent basketball players. J. Sports Sci. 2013, 31, 196-203. [CrossRef] [PubMed]

41. Erčulj, F.; Bračič, M. Differences in the Development of the Motor Abilities of Young Elite European and Slovenian Female Basketball Players. Kinesiol Slov. 2009, 15, 24-32.

42. Ferioli, D.; Rampinini, E.; Bosio, A.; La Torre, A.; Maffiuletti, N.A. Peripheral Muscle Function During Repeated Changes of Direction in Basketball. Int. J. Sports Physiol. Perform. 2019, 14, 739-746. [CrossRef] [PubMed]

43. Aksovic, N.; Kocic, M.; Beric, D. Explosive power in basketball players. Phys. Educ. Sport 2020, 18, 119-134.

44. Arede, J.; Ferreira, A.P.; Gonzalo-Skok, O.; Leite, N. Maturational Development as a Key Aspect in Physiological Performance and National-Team Selection in Elite Male Basketball Players. Int. J. Sports Physiol. Perform. 2019, 14, 902-910. [CrossRef]

45. Lockie, R.G.; Jeffriess, M.D.; McGann, T.S.; Callaghan, S.J.; Schultz, A.B. Planned and reactive agility performance in semiprofessional and amateur basketball players. Int. J. Sports Physiol. Perform. 2014, 9, 766-771. [CrossRef] [PubMed]

46. Arede, J.; Ferreira, A.P.; Esteves, P.; Gonzalo-Skok, O.; Leite, N. Train Smarter, Play More: Insights About Preparation and Game Participation in Youth National Team. Res. Q. Exerc. Sport 2020, 91, 583-593. [CrossRef]

47. Garcia-Gil, M.; Torres-Unda, J.; Esain, I.; Duñabeitia, I.; Gil, S.M.; Gil, J.; Irazusta, J. Anthropometric Parameters, Age, and Agility as Performance Predictors in Elite Female Basketball Players. J. Strength Cond. Res. 2018, 32, 1723-1730. [CrossRef]

48. Fort-Vanmeerhaeghe, A.; Montalvo, A.; Latinjak, A.; Unnithan, V. Physical characteristics of elite adolescent female basketball players and their relationship to match performance. J. Hum. Kinet 2016, 53, 167-178. [CrossRef] [PubMed]

49. Ben Abdelkrim, N.; Castagna, C.; Jabri, I.; Battikh, T.; El Fazaa, S.; El Ati, J. Activity profile and physiological requirements of junior elite basketball players in relation to aerobic-anaerobic fitness. J. Strength Cond Res. 2010, 24, 2330-2342. [CrossRef]

50. Dawes, J.; Marshall, M.; Spiteri, T. Relationship between pre-season testing performance and playing time among NCAA DII basketball players. Sports Exerc. Med. 2016, 2, 47-54. [CrossRef]

51. Ramos, S.; Volossovitch, A.; Ferreira, A.P.; Barrigas, C.; Fragoso, I.; Massuça, L. Differences in Maturity, Morphological, and Fitness Attributes Between the Better- and Lower-Ranked Male and Female U-14 Portuguese Elite Regional Basketball Teams. J. Strength Cond. Res. 2020, 34, 878-887. [CrossRef]

52. Manuel Clemente, F.; Conte, D.; Sanches, R.; Moleiro, C.F.; Gomes, M.; Lima, R. Anthropometry and fitness profile, and their relationships with technical performance and perceived effort during small-sided basketball games. Res. Sports Med. 2019, 27, 452-466. [CrossRef]

53. Guimarães, E.; Ramos, A.; Janeira, M.A.; Baxter-Jones, A.D.G.; Maia, J. How Does Biological Maturation and Training Experience Impact the Physical and Technical Performance of 11-14-Year-Old Male Basketball Players? Sports 2019, 7, 243. [CrossRef] 